\title{
O processo civil brasileiro eletrônico na sociedade em rede: uma análise a partir da herança racionalista
}

\author{
The brazilian electronic civil procedure in society \\ network: an analysis from the rationalist heritage
}

\author{
Alexsandra Gato Rodrigues* \\ Cristiano Becker Isaia* \\ Danielli Gadenz ${ }^{* *}$
}

\section{Resumo}

Em um mundo conectado, graças à internet, o processo civil vem enfrentando problemas nunca antes experimentados. Ocorre que o atual sistema processual tem tido dificuldade em tutelar com efetividade os novos direitos, em razão da profunda imersão que ainda sofre nas suas raízes racionalistas. Algumas modificações legislativas vêm buscando dar mais celeridade ao processo, tal qual a Lei do Processo Eletrônico, n 11.419/06, que surge como uma tentativa de abertura do Judiciário para o século XXI. Todavia, questiona-se se essa lei realmente modifica a jurisdição processual atual, de modo a garantir a efetividade à prestação jurisdicional nos casos envolvendo a sociedade em

Mestranda do Programa de Pós-graduação em Direito da Universidade Federal de Santa Maria, na área de concentração "Direitos Emergentes da Sociedade Global", vinculada à linha de pesquisa "Direitos na Sociedade em Rede". Advogada, Mestre em Desenvolvimento. Santa Maria - RS - Brasil. E-mail: alexsa41514@gmail.com

* Doutor em Direito Público pela Universidade do Vale do Rio dos Sinos (UNISINOS). Professor Adjunto lotado no Programa de Pós-Graduação em Direito (Mestrado) e no Departamento de Direito da Universidade Federal de Santa Maria (UFSM). Professor Adjunto do Curso de Direito do Centro Universitário Franciscano (UNIFRA). Coordenador do NEAPRO/UFSM (Núcleo de Estudos Avançados em Processo Civil da Universidade Federal de Santa Maria) Responsável pelo projeto Processo civil e $(m)$ crise: o esgotamento do procedimento ordinário na satisfação dos direitos sociais, financiado pela FAPERGS, registrado sob n. ${ }^{012 / 0880-8 . ~ S a n t a ~ M a r i a ~-~ R S ~-~}$ Brasil. E-mail: cbisaia@gmail.com

*** Possui graduação em Direito pela Universidade Federal de Santa Maria (2012) e mestrado em Programa de Pós-graduação em Direito pela Universidade Federal de Santa Maria (2014). Santa Maria - RS - Brasil. Email: danigadenz@gmail.com 
rede. No entanto, vislumbra-se ainda um longo caminho ao processo civil, que necessita desapegar-se do paradigma racionalista, ao qual está preso.

Palavras-chave: Processo civil. Efetividade. Processo eletrônico. Sociedade em rede.

\section{Abstract}

In a connected world, thanks to the internet, the civil procedure has been facing problems never before experienced. Happens that the current system have difficulty to safeguard effectively the new rights, because of deep the immersion that the civil procedure still suffers of its rationalist roots. Some legislative changes have been trying to give more speed to the process, like the Law of the electronic process, $n$. 11.419/06 which arises as an attempt to open the judiciary for the XXI century. However, it is questionable whether this law actually modifies the current procedural jurisdiction, to ensure the effectiveness of adjudication in cases involving the network society. Nevertheless, it still has a long way to the civil procedure, which requires letting go of the rationalist paradigm in which it's stuck.

Keywords: Civil procedure. Effectiveness. Electronic process. Network society.

\section{Introdução}

O direito processual civil brasileiro contemporâneo atravessa duas grandes crises. A (falta de) celeridade do processo é uma delas, considerando o grande número de processos que atualmente tramitam. $A$ segunda diz respeito à efetividade (satisfação), pois de nada adianta um processo rápido se ao final o autor da ação não consegue a realização do seu direito.

Ao longo dos últimos anos, foram realizadas várias alterações na legislação processual, na tentativa de combater esses problemas que comprometem a credibilidade do Judiciário. Na esteira das reformas normativas, elevou-se ao patamar constitucional o direito à celeridade do processo e, paralelamente, buscaram-se mecanismos concretos de efetivação da norma magna. É nesse contexto que a lei 11.419/06 surge 
como uma tentativa de abertura do Judiciário para o século XXI. Com ela, termos como "on-line", "assinatura eletrônica", "assinatura digital", "certificados digitais" e "internet" entraram definitivamente para o léxico jurídico brasileiro e, mais que isso, passaram a ser o instrumento de trabalho cotidiano dos profissionais da área.

O processo, autêntica ferramenta de natureza pública, indispensável para a realização da justiça e da pacificação social, não pode ser compreendido como mera técnica. Ele deve ser visto como um instrumento de realização de valores, inclusive constitucionais. Por isso, impõe-se considerá-lo como um direito constitucional aplicado.

Nos dias atuais, cresce a importância dessa concepção. Se atentarmos para a íntima conexidade entre a jurisdição e o instrumento processual na aplicação e proteção dos direitos e garantias assegurados na Constituição, observa-se que não se trata mais de apenas conformar o processo às normas constitucionais, mas de empregá-las no próprio exercício da função jurisdicional, com reflexo direto no seu conteúdo, naquilo que é decidido pelo órgão judicial e na maneira como o processo é por ele conduzido.

As profundas transformações econômicas, políticas, sociais e culturais, tanto no plano científico como tecnológico e operacional, que vem ocorrendo em ritmo cada vez mais acelerado, requerem uma mudança de atitude do Judiciário e dos magistrados para que possam corresponder aos atuais anseios da sociedade. Percebendo a complexidade da sociedade contemporânea, considerada, entre outros epítetos, sociedade de risco, e marcada pela cultura da incerteza, colocam-se os desafios à exigência de prestação de tutela jurisdicional adequada e efetiva aos direitos difusos, coletivos e individuais homogêneos dos consumidores.

No campo do processo civil, os juristas se deparam com um novo dilema: a busca pela efetividade processual e a necessidade de readequá-lo para a tutela dos novos direitos decorrentes da realidade digital, ágil e dinâmica. Contudo, o processo civil tradicional, moroso, 
próprio do procedimento ordinário, sedimenta-se em valores liberais racionalistas e não se coaduna com a nova realidade.

A celeridade processual pressupõe decisões dadas em um prazo razoável, mediante um julgamento com qualidade. A jurisdição, diante da complexidade da sociedade contemporânea, da emergência de novos direitos, de inflação legislativa e da disfuncionalidade da Constituição não pode mais satisfazer as demandas sociais com o uso alargado da tutela repressiva gerada à luz da ideologia racionalista.

Nesse contexto, surge o processo eletrônico como locus alternativo de celeridade/efetividade processual em meio à complexidade da sociedade em rede. Assim, propõe-se o seguinte questionamento: está o processo civil eletrônico brasileiro preparado para enfrentar, sob a ótica dos direitos fundamentais, as questões oriundas da sociedade em rede?

Para enfrentar esse questionamento, utilizar-se-á como teoria de base o método dialético, realizando uma interpretação dinâmica da realidade processual brasileira, considerando os fatos em seu contexto social, político, econômico e cultural. Empregou-se, na construção do presente trabalho, a técnica de pesquisa bibliográfica, realizando-se um apanhado doutrinário sobre o tema.

Com isso, inicia-se a exposição com uma breve abordagem acerca da sociedade em rede, na perspectiva dos direitos fundamentais.

\section{A sociedade em rede e os direitos fundamentais}

Globalização é um dos conceitos em voga na atualidade, sendo seu significado, na maioria das vezes, reduzido ao aspecto econômicofinanceiro. Pode-se definir globalização como "a intensificação de relações sociais mundiais que unem localidades distantes de tal modo que os acontecimentos locais são condicionados por eventos que acontecem a muitas milhas de distância e vice-versa" (GIDDENS, 1991, p. 64). 
A globalização remete a um processo social, econômico, cultural e demográfico que se instala no coração das nações e as transcende ao mesmo tempo, de tal forma que uma atenção limitada aos processos, às identidades e às unidades de análises locais, faz incompleta a compreensão local. Assim, para Pacheco (1995, p. 103):

Globalização não é um fenômeno que possa ser explicado linear ou unilateralmente. A ele convergem muitos e diversos fatores; é um processo em marcha, não finalizado, um processo em transição a uma nova fase do capitalismo, cujo significado esta muito longe de ser unívoco.

Nesse sentido, a globalização não é uma ideologia, tampouco um programa econômico a defender-se, e sim um fenômeno que está ocorrendo no mundo. Como efeito, tem-se a "redução de fronteiras", visto que o mundo parece encolher cada vez mais, em razão da agilidade que a tecnologia permite, seja na transmissão de informações, seja na velocidade dos transportes, etc. A indústria da informática e da telecomunicação vive uma explosão sem precedentes, o que acarreta baixo custo e sua consequente popularização. Paralelamente, começase a esboçar uma convergência entre a infraestrutura de comunicação e a indústria, à medida que ambas se digitalizam. É essa conjunção que torna possível um mundo globalizado, o que condenará à morte a localização geográfica.

Acompreensão da globalização e sua ligação com a informatização judicial é um importante passo para compreender a própria visão clássica do Direito, o qual está (ou deveria estar) substancialmente interligado aos fenômenos sociais.

O contexto do século XXI trouxe consigo profundos e significativos paradigmas culturais, dentre eles, a interação multiforme propiciada por mecanismos virtuais oferecidos pela rede mundial de computadores, mais conhecida pelo termo world wide web. A influência desses paradigmas ocasionou uma contínua redefinição das estruturas sociais, sendo que instituições governamentais e privadas, a partir das oportunidades criadas com a informatização, adotaram, integralmente, a linguagem 
virtual como forma de executar os procedimentos condizentes com suas atribuições (IOCOHAMA; JUNIOR; SELETI; MENDES; SHIMIT, 2010).

É nesse contexto que a sociedade em rede insere-se. Manuel Castells (1999) dá à sociedade contemporânea a denominação de sociedade em rede por tratar-se de uma sociedade globalizada, centrada no uso e na aplicação de informação e conhecimento, tendo por base a revolução na tecnologia da informação, que implica em mudanças nas relações sociais, políticas e econômicas, inserida em todas as esferas da atividade humana. Para o autor, "devemos localizar este processo de transformação tecnológica revolucionária no contexto social em que ele ocorre e pelo qual está sendo moldado" (CASTELLS, 1999, p. 24).

Para Angela Espindola e Priscila Werner, a sociedade contemporânea exige que o direito trace novas perspectivas, adaptandose à nova realidade:

O contexto atual da sociedade contemporânea exige do direito novas perspectivas no que concerne a forma de pensar, aplicar e interpretar a lei. Assim, o direito para atender os clamores da sociedade onde tudo é urgente e incerto, precisa adaptar-se as essas novas exigências. Entretanto, isso somente é possível quando se (re)pensa criticamente alguns conceitos e dogmas vigentes na ciência jurídica. Assim, o direito e seu processo enquanto instrumento para a pacificação dos conflitos sociais, prescindem de uma abertura as transformações sociais para encontrar novas respostas. (ESPINDOLA; WERNER, 2006, p. 77)

Há muito já se tem escrito acerca das dificuldades enfrentadas para que o processo judicial pudesse atender com rapidez à sua finalidade. Como bem resumido por Cruz e Tucci (2001, p. 16), "o fator tempo, que permeia a noção de processo judicial, constitui, desde há muito, a mola propulsora do principal motivo de crise da justiça, lembrando Fazzalari com a comparação da demora do processo como a (tormenta das tormentas)".

Assim, a necessidade de instituir meios eficazes de proteção dos direitos implica num constante repensar do processo judicial. 
Disso decorrem as diversas reformas que ele tem recebido, alterandose procedimentos, atos processuais e ações. Não é por menos que se regulamentou politicamente a garantia de um processo judicial célere, por meio da alteração constitucional realizada pela Emenda Constitucional n 45/2004, acrescendo o inciso LXXVIII ao artigo $5^{\circ}$ da Carta Magna, estabelecendo como garantia fundamental que "a todos, no âmbito judicial e administrativo, são assegurados a razoável duração do processo e os meios que garantam a celeridade de sua tramitação" (BRASIL, 1988).

Sabidamente, a promulgação da Constituição de 1988 foi precedida de um período marcado por forte autoritarismo, o que contribuiu para a atribuição de tamanha importância aos direitos fundamentais. A relevância atribuída aos direitos fundamentais, o reforço de seu regime jurídico e até mesmo a configuração do seu conteúdo são frutos da reação do Constituinte, das forças sociais e políticas nele representadas, ao regime de restrição e até mesmo de aniquilação das liberdades fundamentais (SARLET, 2008, p. 73).

Em razão disso, o parágrafo $1^{\circ}$ do artigo $5^{\circ}$ da Constituição Federal confere aplicação imediata às normas reguladoras dos direitos e garantias fundamentais, entre elas, a garantia do acesso à justiça, os princípios da efetividade, da duração razoável do processo e dos meios que garantam a celeridade de sua tramitação. Além de garantir a aplicabilidade dos direitos e garantias individuais, o Constituinte incluiuos no rol das cláusulas pétreas, previsto no parágrafo $4^{\circ}$ do artigo 60 da Constituição Federal, "impedindo a supressão e erosão dos preceitos relativos aos direitos fundamentais pela ação do poder Constituinte derivado" (SARLET, 2008, p. 76).

Diante dessas previsões constitucionais, podemos observar a importância que o ordenamento jurídico e o sistema processual brasileiro conferem aos direitos fundamentais, visto que esses são pressupostos básicos para a dignidade humana. Cuida-se, portanto, de direitos inerentes à própria noção de direitos básicos da pessoa, que constituem a base jurídica da vida humana. 
Os direitos fundamentais, por natureza, são destinados a todos. Constituem uma condição generalizadora aos seres humanos, a tal ponto que não se admite que tais direitos sejam destinados apenas a uma classe ou categoria de pessoas.

Ingo Wolffgang Sarlet (2008. p. 66) identifica que os direitos fundamentais transmitem a ideia de democracia:

Os direitos fundamentais podem ser considerados pressupostos, garantia e instrumento do princípio democrático da autodeterminação do povo por intermédio da cada indivíduo, mediante reconhecimento do direito de igualdade (perante a lei de oportunidades) de um espaço de liberdade real, bem como por meio da outorga do direito à participação (com liberdade e igualdade). Portanto, do vínculo entre o Direito Constitucional e o Direito Processual Civil nasce para o cidadão uma série de garantias inerentes ao estado democrático (LONGO, 2003). Desse modo, o processo, na condição de autêntica ferramenta de natureza pública, é indispensável para a realização da justiça e da pacificação social, devendo ser considerado um direito constitucional aplicado. Assim, ele não pode ser compreendido como mera técnica, mas como instrumento de realização de valores e especialmente valores constitucionais (OLIVEIRA, 2003, p. 261).

Sob essa ótica, cabe ao Poder Judiciário cumprir seu papel na construção do direito em concreto, não se limitando à declaração da vontade da lei, mas atuando no propósito de uma constituição-cidadã, em observância ao rol de direitos e garantias que nenhum poder, no exercício de sua função precípua, pode se afastar ou negar vigência, sob pena de se manter limitado aos propósitos de um Estado Liberal, modelo ultrapassado, negando a constituição de um novo pacto social, ínsito ao Estado Democrático de Direito (MACEDO, 2008). 
É óbvio que as alterações legislativas no campo do Direito Processual devem, em certa medida, buscar resultados práticos para a melhoria da aplicação da tutela, mas isso não significa que se possa negligenciar o papel importantíssimo que o processo possui como estrutura dialógica de formação de provimentos e garantidora de direitos fundamentais.

O processo se apresenta como locus privilegiado para a concretização do convívio em sociedade, o que importa conceber os instrumentos processuais e a própria decisão do juiz como fruto de um diálogo democrático convergente para uma nova legitimidade. Repensar o processo civil na sociedade em rede é, sem dúvida, um desafio que se impera.

\section{O processo civil brasileiro eletrônico versus um processo civil herdado do racionalismo do Estado Liberal}

A conflituosidade no ambiente social tem aumentado em níveis consideráveis, assim como o número de processos. A Constituição Federal atribuiu ao Poder Judiciário o papel de dirimir controvérsias e consagrou, ao mesmo tempo, o princípio do acesso à justiça a todos. Mas não só isso, juntamente com o acesso à Justiça, garante a todos o direito a uma tutela jurisdicional adequada e em tempo razoável.

Da necessidade de aprimorar a prestação jurisdicional e, assim, satisfazer os anseios sociais que, manifestadamente, demonstravam seu desagrado com a morosidade na entrega da tutela Estatal-jurisdicional, surgiu, imbuída de espírito inovador, a Emenda Constitucional $n^{\circ} 45$, de 8 de dezembro de 2004 (EC n 45/04).

Somando-se à mencionada emenda, uma série de alterações legislativas ocorreu. Mas a grande novidade foi o advento da Lei $\mathrm{n}^{\circ}$ 11.419, de 19 de dezembro de 2006, que diz respeito à implantação do processo judicial eletrônico e que, com amparo no desenvolvimento da Tecnologia da Informação, mostra-se uma ferramenta inegavelmente importante na busca por melhor efetividade do sistema judiciário 
brasileiro, tendo em vista que a humanidade alterou significativamente sua forma de se relacionar e interagir transformando-nos em sociedade da informação, amplamente influenciada pela revolução digital (BRASIL, 2006).

Para uma teorização do direito processual, será preciso enfrentar a questão da jurisdição em ambientes informatizados. Esta se apresenta como a maior preocupação quando se está quebrando um paradigma dentro da sociedade da informação. Está-se diante de uma nova sociedade da informação, ou pelo menos, diante de novas concepções, antes não alcançadas por nossos antepassados, nem mesmo na ficção científica, que pode ser concebida com a terminologia de sociedade da informação (ALMEIDA FILHO, 2010).

Observa-se que, ainda hoje o processo civil mantém dogmas do século XIX, desde o seu nascimento como ciência autônoma, mantendo vivas tradições seculares e ultrapassadas para a contemporaneidade, realizando a desvinculação entre direito material e processo, estudando o direito sem levar em consideração os valores da Constituição e do direito material, tornando o processo obsoleto e incapaz de responder as "novas" situações substanciais existentes na sociedade, negando, portanto, o direito fundamental à tutela jurisdicional efetiva.

A atual falta de efetividade na prestação jurisdicional é a situação problemática que serve como ponto de partida para compreender - e, então, superar - os obstáculos que o paradigma racionalista impõe ao direito processual civil contemporâneo.

O Estado Liberal do século XVIII, através da formação de um Estado de Direito, significou uma profunda ampliação da compreensão do sentido do princípio de acesso à justiça. As velhas figuras de jurisdição, direito material e direito processual construídas em relação ao Estado, ao longo da história, transformaram-se na modernidade (CHEVALLIER, 2009).

Assim, faz-se necessário:

Uma releitura do processo civil brasileiro, de tradição romano canônica, da perspectiva fenomenológico-hermenêutica 
pode conduzir a identificação e a superação do paradigma racionalista, das filosofias liberais e do pensamento linear -cartesiano, aproximando o direito processual civil da Constituição e dos direitos fundamentais e reduzindo o fosso existente entre discurso e prática da concretização de direitos". (ESPINDOLA, 2008, p. 28)

Os pensadores racionalistas do Estado liberal eram matemáticos e o conhecimento humano levava em conta apenas a razão. O desenvolvimento intelectual originou as ideias de liberdade política e econômica que eram defendidas pela burguesia. Os avanços tecnológicos levavam em conta a razão como sendo capaz de alcançar qualquer conhecimento. As ideias iluministas favoreciam o entendimento das ciências como equações algébricas, necessitando de sistematização e ordenação. As codificações surgem e refletem na tendência das cognições exaurientes, dificultando a utilização das tutelas de urgência.

Buscava-se, ainda que inconscientemente, a segurança jurídica. O juiz deveria ser "a mera boca que pronunciava as palavras da lei" numa tradição montesquiana (CAPPELLETTI, 1993, p. 32).

Esse modo de conceber o direito, como fonte adstrita e vinculada à lei, compromete o aprimoramento do processo civil para atender às demandas atuais. Baptista da Silva (2004) adverte como solução dos problemas atuais a utilização de remédios ultrapassados. Desse modo, é predominante o pensamento linear do século XVIII, obstaculizando-se a tentativa de adequação processual aos novos litígios de uma sociedade eminentemente complexa. Percebe-se uma estagnação do direito frente às ideologias passadas e isso também explica o descompasso entre as transformações sociais e o direito. Devido à racionalização do direito, as reformas não tutelam tempestivamente os clamores da sociedade. $\mathrm{E}$ este fato é atrelado à história porque não se consegue desvincular do paradigma racionalista.

O processo civil, segundo Baptista da Silva (2004), a partir das filosofias do século XVII, priorizou o valor "segurança" como exigência fundamental à construção de um Poder Judiciário eficiente. Com efeito, 
desde sua concepção, é essencial à legitimidade do procedimento ordinário-plenário-declaratório o contraditório prévio, segundo o qual o juiz somente poderá julgar depois de ter ouvido ambas as partes (cognição exauriente), porque assim é que estará habilitado a descobrir a vontade da lei. Essa ritualística nada mais é do que a representação do racionalismo, através do qual se entende possível alcançar a verdadeira vontade da lei, que teria um sentido unívoco prestes a ser demonstrado pelo juiz através do método adequado. Método esse que privilegia a cognição exauriente, fruto da idealização de um juiz "boca da lei" e motivo pelo qual se vê um impedimento à criação de uma genuína tutela preventiva (que agilizaria a tramitação da demanda). A codificação afastou o direito dos conflitos sociais e, por sua vez, "o processo congelou-se no tempo", atrelado ainda hoje ao "componente ideológico inerente à ética do liberalismo", segundo Baptista da Silva (2004, p. 35). Ou seja, o processo continua possuindo caráter autoritário e algemado ao paradigma racional, preterindo decisões sumárias.

Para tanto, inicialmente, o processo deve ser compreendido a partir de sua história, de sua origem, e estar atento às brutais mudanças sociais, procurando adaptar-se às novas exigências. Com isso, surge a necessidade de demandas céleres, não sendo plausível a utilização de cognições exaurientes como regra de procedimento, devido à morosidade e ineficiência para resolução dos conflitos. Nesse contexto, imperam-se as formas sumárias de cognição, como as tutelas de urgência, por atenderem rapidamente ao direito material buscado em juízo, ultrapassando a cognição exauriente do procedimento ordinário. Nesse contexto,

[...] a crise do Estado (institucional) e do Judiciário (efetividade no atendimento) advém de um sistema despreparado para atender uma sociedade que busca 0 Estado para resolver seus conflitos. É nesse contexto que o processo virtual veio adaptar o processo ao tipo de litígio que se tem na sociedade atualmente, ou seja, aquele que necessita de um sistema jurídico prestador de serviços céleres e eficazes, de modo que, na esteira da teoria de Cappelletti, possa se vislumbrar um efetivo acesso à justiça, 
compreendido por meio do fator tempo, dentro do princípio da razoável duração do processo. (ISAIA e PUERARI, 2012, p. 130)

Assim, pode-se afirmar que o processo eletrônico no direito brasileiro tem inspiração nessa demanda pela atenção ao tempo do processo. No contexto histórico da pretensão de se agilizar o processo judicial, despertou-se o interesse em utilizar os meios eletrônicos possíveis, contando com a eficácia das comunicações que o mesmo viabiliza, somando-se ao princípio da economia, envolvendo diminuição de custos com papel e recursos.

Em vigor desde maio de 2007, a referida lei tem causado grandes transformações no Poder Judiciário, e está destinada a mudar o padrão de acúmulo de papéis decorrentes dos autos em documentos eletrônicos. Inúmeras notícias apontam para esse fim e a realidade virtual para o processo judicial está muito mais próxima do que se poderia imaginar.

Entretanto, se essa corrida para a informatização do processo judicial está se destacando no plano técnico, com programas e alterações estruturais, tem surgido o questionamento de como serão resolvidas certas questões envolvendo direitos fundamentais do próprio processo, como a igualdade, o controle dos atos processuais pelo princípio da publicidade, a celeridade e economia processuais, a oralidade e a imediatidade, no contexto do importante e geral princípio do devido processo legal os humanos.

Com efeito, o processo civil evoluiu de uma concepção individualista (a qual servia apenas para a busca do direito da parte) para uma tendência social e, além disso, chegou ao ponto de colocar em questão sua própria finalidade, de maneira que a doutrina tem passado a insistir na importância da proteção do direito material, mais do que a simples preocupação com as formalidades do processo. As relações contemporâneas, cada vez mais complexas, guiam as interpretações legais ao contrário, porquanto refletem as diversidades de compreensões subjetivo-culturais. 
Nessa vertente, o problema que se põe a qualquer jurista colocado no meio desses dois mundos é o de não saber como resolver em termos juridicamente rigorosos e constitucionalmente não capitulacionistas as questões da ponderação de direitos e bens por meio de uma balança que já não tem mais dois pratos, mas que digitaliza, em termos reais, interesses múltiplos e múltiplos interesses (CANOTILHO, 2003).

Por isso, a efetividade do processo constitui um direito fundamental, devendo os textos normativos infraconstitucionais processuais ser revistos e reinterpretados em conformidade com o paradigma do Estado Democrático de Direito, não podendo mais o processo jurisdicional ser um obstáculo à realização do direito material, mas antes condição de possibilidade para a realização dos direitos previstos na ordem jurídica (STRECK, 2007).

A construção de um processo civil atento ao paradigma do Estado Democrático de Direito, à concretização dos direitos, aos princípios processuais constitucionais e, consequentemente, ao "acontecer" da Constituição precisa superar o peso cultural do paradigma racionalista bem como os valores liberais individualistas ainda remanescentes. Assumir essa preocupação é condição de possibilidade para a defesa da jurisdição estatal e da democracia sem desconsiderar o contexto histórico em que sociedade moderna - complexa e pluralista - se encontra. Espíndola e Cunha (2011. p. 89) aduzem que:

As garantias constitucionais processuais (ou direitos fundamentais processuais) asseguram um mecanismo adequado ao tratamento dos conflitos ou à sua prevenção, sendo garantias de meio e de resultado, pois estão diretamente relacionadas não apenas aos instrumentos processuais adequados, como também a um resultado efetivo. Não se trata, evidentemente, de direito ao resultado favorável, tampouco apenas de exercício do direito de acesso ao judiciário ou direito de petição. É direito à efetividade da jurisdição por meio de um processo jurisdicional democrático. 
Dessa forma, o direito processual civil deve ter a capacidade de construir-se e reconstruir-se a partir do tempo do direito, voltandose também para o futuro e para o coletivo. Diante disso, há que se investigar uma nova forma de atuação da jurisdição por meio das tutelas preventivas e coletivas, primando pelos direitos fundamentais processuais. No dizer de Cristiano Isaia e Adriano Puerari (2012, p.129):

Por isso, ainda que, prima facie, a aceleração de tramitação do e-Processo pareça ir exatamente ao encontro do direito fundamental ao processo judicial de razoável duração, deve-se atentar para o fato de que a realização do processo no tempo moderado tem como condição de procedibilidade a efetividade da prestação jurisdicional, no âmbito do largo acesso ao judiciário. Ou seja, de nada adianta o seu (do processo) rápido desenvolvimento, se não observadas as garantias constitucionais de uma prestação jurisdicional de qualidade, atenta aos direitos fundamentais do cidadão principalmente o de acesso à justiça.

Dessa forma, as alterações mais significativas que trouxe a Lei $\mathrm{n}^{\circ}$ 11.419, de 2006 ao Processo Civil dizem respeito ao combate à morosidade judicial. Todavia, não se operou transformação radical ao Código de Processo Civil, tendo em vista que os prazos, os recursos, as ações e os procedimentos permaneceram os mesmos. A virtualização do processo judicial, com sua proposta de aceleração do trâmite do procedimento, não resolve o problema de lentidão do processo, já que, do ponto de vista ontológico, as alterações não repercutiram em nada ao processo civil (ISAIA; PUERARI, 2012).

Diante da realidade da sociedade em rede, o processo precisa se adequar para tutelar adequadamente os conflitos daí oriundos. Não é possível que o processo civil que temos hoje, de cariz racionalista, cunhado com bases filosóficas próprias do iluminismo (séculos XVII e XVIII), seja capaz de conceder uma tutela efetiva às situações originadas no ambiente virtual do século XXI.

Como inovação, a legislação brasileira lança mão do processo eletrônico, através da lei $n^{\circ} 11.419$, de 2006. Mas o que isso significa 
realmente? Trata-se de uma mera "virtualização" do processo? Os autos deixam de ser de papel e passam a integrar um sistema informatizado? Claramente, isso não é suficiente para conceder aos cidadãos uma nova tutela processual. O Poder Judiciário continua despreparado para lidar com situações oriundas da sociedade em rede.

É isso o que Leonardi conclui, quando salienta que a sociedade em rede implica na necessidade de reconhecer as limitações do sistema jurídico atual e formular soluções eficientes para as questões postas em discussão:

A internet não exige apenas novas soluções jurídicas para os novos problemas, ela também afeta a maneira como os problemas e as soluções jurídicas devem ser analisados. Ao romper com paradigmas jurídicos tradicionais e desafiar os mecanismos convencionais de tutela, a Rede representa um dos principais objetos de estudo dos doutrinadores preocupados com essa nova realidade social. A principal dificuldade, portanto, é oferecer propostas de soluções eficientes para os problemas práticos que se apresentam, reconhecendo as limitações do sistema jurídico. [...] Exigese que o jurista reveja as premissas de sua dogmática, reconhecendo as mudanças decorrentes da globalização e adotando as medidas úteis ou necessárias, de modo a acompanhar a revolução econômica e tecnológica. (LEONARDI, 2012, p. 39)

Atento para as dificuldades que o processo civil vem sofrendo para tutelar as questões da sociedade em rede, Isaia (2012, p. 262) aponta que "o processo civil do século XXI carece de um pensar a partir do novo modelo de organização social que ser apresenta".

Assim, não basta que o processo tramite em meio digital, ele tem que ser pensado de forma diferente, desapegando-se do paradigma racionalista e encarando o século XXI. 


\section{Conclusão}

$\mathrm{Na}$ medida em que o avanço das tecnologias da informação, em especial da internet, revolucionou a sociedade contemporânea, o direito também é influenciado. Diante de uma realidade processual atrelada a teorias dos séculos XVIII e XIX, observa-se que o processo civil ordinário, que tem por característica a morosidade, encontra-se totalmente desadaptado às novas realidades sociais. É nesse contexto que o processo civil necessita adaptar-se para, no cenário atual, cheio de novos ambientes processuais como a internet, garantir aos seus jurisdicionados uma tutela ágil e eficiente, a partir da criação de novas estruturas capazes de regular tais situações. Verifica-se, então, um dilema latente para os juristas no mundo contemporâneo: a busca pela efetividade processual e a necessidade de readequá-lo para a tutela dos novos direitos decorrentes das novas tecnologias, especialmente a internet.

O processo civil brasileiro atualmente encontra-se em um momento extremamente paradigmático. Invariavelmente, ele sofre influências da sociedade informacional ou "sociedade em rede" (Manuel Castells) e busca adaptar-se à realidade dos novos meios de comunicação, mas mesmo assim ele permanece preso a antigos dogmas do passado, como a plenariedade, a cognição exauriente, a ordinariedade e a visão eminentemente declaratória.

No ambiente da internet, o alcance da informação vai além do mundo virtual, refletindo na vida "real" do indivíduo, razão pela qual necessita de uma resposta eficiente. Entra aí o papel do direito e do processo como meio de consecução da justiça.

As vantagens introduzidas pela lei do processo digital ao Processo Civil Brasileiro (virtualização) não podem ocorrer à margem dos princípios constitucionais do processo, especialmente o de acesso à justiça e o da razoável duração do processo, que se refletem na eficiência do Judiciário. No entanto, as modificações trazidas à processualística civil pela instituição do processo judicial eletrônico não alteraram a 
substância do procedimento, ainda baseado na herança racionalista de sacralização do rito ordinário-plenário-declaratório.

Respondendo ao questionamento proposto neste trabalho - se está o processo civil eletrônico brasileiro preparado para enfrentar, sob a ótica dos direitos fundamentais, as questões oriundas da sociedade em rede -, conclui-se que a codificação do processo eletrônico não resolve os problemas estruturais que envolvem o direito processual civil. Portanto, preconiza-se uma (re)leitura do direito processual à luz de novas estruturas políticas, jurídicas e sociais mais adequadas aos desafios impostos pela sociedade da era da informação.

\section{Referências}

ALMEIDA FILHO, J. C. A. Processo eletrônico e teoria geral do processo eletrônico: a informatização judicial no Brasil. 3. ed. Rio de Janeiro: Forense, 2010.

SILVA, Ovidio Baptista da. Processo e ideologia: o paradigma racionalista. Rio de Janeiro: Forense, 2004.

BRASIL. Constituição (1988). Diário Oficial da União, Brasília, DF, 15 out. 1988. Disponível em: <http://www.planalto.gov.br/ccivil_03/ Constituicao/Constituiçao.htm>. Acesso em: 5 maio 2013.

BRASIL. Lei no 11.419, de 19 de dezembro de 2006. Diário Oficial da União, Brasília, DF, 20 dez. 2006. Disponível em: <http://www.planalto. gov.br/ccivil_03/_ato2004-2006/2006/lei//11419.htm>. Acesso em: 5 maio 2013.

CANOTILHO, José Joaquim Gomes. Civilização do direito constitucional ou constitucionalização do direito civil? A eficácia dos direitos fundamentais na ordem jurídico civil no contexto do direito pósmoderno. In: GRAU, Eros Roberto; GUERRA FILHO, Willis Santiago. Direito Constitucional: estudos em homenagem a Paulo Bonavides. São Paulo: Malheiros, 2003. p. 108-115 
CAPPELLETTI, Mauro. Juízes legisladores? Tradução de Carlos Alberto Álvaro de Oliveira. Porto Alegre: Sergio Fabris Editor, 1993.

CASTELLS, Manuel. A sociedade em rede. São Paulo: Paz e Terra, 1999.

CHEVALLIER, Jacques. O Estado pós-moderno. Tradução de Marçal Justen Filho. Belo Horizonte: Fórum, 2009.

TUCCI, José Rogério Cruz e. A causa petendi no processo civil. São Paulo: Revista dos Tribunais, 2001.

ESPÍNDOLA, Angela Araújo da Silveira. Superação do racionalismo no processo civil enquanto condição de possibilidade para a construção das tutelas preventivas: um problema de estrutura ou função? (ou: por que é preciso navegar em direção à ilha desconhecida e construir o direito processual civil do estado democrático de direito?). 2008. 305 f. Tese (Doutorado em Direito) - UNISINOS, 2008.

ESPÍNDOLA, Angela Araújo da Silveira; CUNHA, Guilherme Cardoso Antunes. O processo, os direitos fundamentais e a transição do estado liberal clássico para o estado contemporâneo. Revista de Estudos Constitucionais, Hermenêutica e Teoria do Direito, São Leopoldo, v. 3, n. 1, p. 84-94, jan./jun. 2011.

ESPÍNDOLA, Angela Araújo da Silveira; WERNER, Priscila Cardoso. As Tutelas de urgência como alternativa à superação do procedimento ordinário. Revista Eletrônica do Curso de Direito da UFSM, Santa Maria, v. 1, n. 1, p. 64-80, mar. 2006.

GIDDENS, Anthony. As conseqüências da modernidade. Tradução de Raul Fiker.São Paulo: UNESP, 1991.

IOCOHAMA, C. H; OLIVEIRA JÚNIOR, Jesuíno Pereira de,; SELETI, K. P; MENDES, N. C. O; SHIMIT, V. A informatização judicial e as garantias fundamentais representadas pelos princípios processuais. Revista Ciências Jurídicas e Sociais UNIPAR, Umuarama, v. 13, n. 1, p. 1948, jan./jun. 2010. 
ISAIA, Cristiano Becker. Processo civil e hermenêutica: a crise do procedimento ordinário e o redesenhar da jurisdição processual civil pela sentença (democrática) liminar de mérito. Curitiba: Juruá, 2012.

ISAIA, Cristiano Becker; PUERARI, Adriano Farias. O processo judicial eletrônico e as tradições (inautênticas) processuais. REDESG - Revista Direitos Emergentes da Sociedade Global, Santa Maria, v. 1, n. 1, p. 120-144, jan./jun. 2012.

LEONARDI, Marcel. Tutela e privacidade na internet. São Paulo: Saraiva, 2012.

LONGO, Luís Antônio. O princípio do juiz natural e seu conteúdo substancial. In: Academia Brasileira de Direito Processual Civil. Porto Alegre, 2003. Disponível em: <www.abdpc.org.br>. Acesso em: 12 dez. 2012.

MACEDO, Elaine Harzheim Macedo. Processo efetivo e tempestivo: reformas processuais ou um novo paradigma de jurisdição? Revista Destaque Jurídico, Gravataí,: v. 7, série 7, p. 211-215, 2008.

PACHECO, P. M. Transformaciones económicas y función de lo político en la fase de la globalización. Anales de la Cátedra Francisco Suárez, Granada, 32, p. 101-138, 1995.

OLIVEIRA, Carlos Alberto Álvaro. Do formalismo no processo civil. 2. ed. São Paulo: Saraiva, 2003.

SARLET, Ingo. A eficácia dos direitos fundamentais. 9. ed. rev. atual. e ampl. Porto Alegre: Livraria do Advogado, 2008.

STRECK, Lênio. Hermenêutica jurídica e(m) crise: uma exploração hermenêutica da construção do direito. Porto Alegre: Livraria do Advogado, 2007.

Recebido em: 13/05/2013

Aprovado em: 16/08/2014 